Principios y Práctica de la Cardiología

\section{Dr. Alexis Lama Toro}

Alfabeta Artes Gráficas, 2012.

ISBN 978-956-7119-56-1

Edición: Septiembre 2012

Páginas: 1056

ISBN: 978-956-7119-56-1

Editorial: Copygrph. www.copygrph.cl

Este es un libro de Cardiología absolutamente original. Su autor es un cardiólogo con gran experiencia clínica y larga trayectoria docente. A diferencia de los textos clásicos, en que se abordan por su orden las distintas metodologías diagnósticas para continuar con la descripción detallada de las patologías cardiovasculares, este libro se inicia con los principios de la práctica médica y continúa con las patologías más comunes de la cardiología ambulatoria. En ambas partes se apoya en notas históricas sobre quienes contribuyeron a definir los principios y los que contribuyeron al avance en el diagnóstico y tratamiento de las enfermedades.

No es habitual que en un libro de práctica médica se reflexione sobre los principios y virtudes que debe cultivar el médico para obtener una adecuada relación con su paciente, partiendo por tener claras las diferencias entre los estados de salud y de enfermedad. Si se tiene en mente las limitaciones que implica una enfermedad, aguda o crónica, se podrá entender mejor la necesidad de las virtudes del acto médico y que resalta el autor: el respeto, la compasión, la honestidad, la humildad y la prudencia, todas ellas orientadas a preservar la dignidad del paciente y a lograr su recuperación física y espiritual. El ejercicio y cultivo de estas virtudes son fundamentales en el quehacer de un médico en su práctica clínica. Tal vez por ello el autor prefirió englobar en un solo libro los principios y la práctica de la Cardiología y en esta primera parte nos trae a la mente la esencia de la vocación médica, la que inspiró en su momento a quienes optaron por esta profesión tan hermosa, pero que requiere de tanta entrega personal al servicio de los enfermos. Aún cuando el ejercicio de la medicina tenga hoy muchos recursos tecnológicos, la práctica médica debe seguir orientándose a consolar, aliviar y, cuando sea posible, contribuir a sanar. Con las mayores expectativas de sobrevida y de mejor calidad de vida, la misión del médico en la preservación de la salud y alivio de la enfermedad adquiere cada vez más importancia. Solo así, comenta el doctor Lama, un médico puede ayudar a un paciente a superar las limitaciones derivadas de una enfermedad y a reintegrarse a una vida plena.

El ejercicio de la profesión médica requiere también de otras habilidades para la correcta interpretación de los avances científicos y de la avalancha de información en torno a la llamada "medicina basada en evidencias". No cabe duda sobre el enorme progreso de la medicina en métodos de diagnóstico, tratamientos farmacológicos, implante de nuevos dispositivos, nuevas técnicas quirúrgicas, etc. Todo ello y el mayor conocimiento sobre los mecanismos que conducen a las enfermedades ha permitido mejorar progresivamente la calidad y las esperanzas de sobrevida. Para incorporar toda esta información sobre nuevo conocimiento en la práctica clínica se requiere de un espíritu crítico y de bases sólidas para apreciar lo importante de lo superfluo. Se necesita, además, de capacidad de observación para reconocer los verdaderos avances de la praxis médica. Para ello el médico debe evitar los conflictos de intereses con las instituciones que promueven nueva información, para llegar a ésta desprovisto de prejuicios. Estos son los conceptos sobre los que reflexiona el autor en la segunda parte de los principios de la práctica médica y que son tan importantes como la primera.

Los capítulos clínicos analizan los motivos de consulta ambulatoria más frecuentes y se resalta en ellos el rigor de la semiología, de la metodología sistemática en el análisis de los síntomas, del examen físico y de los exámenes complementarios, para llegar a un diagnóstico certero. En cada capítulo hay menciones a la historia de las enfermedades y a quienes contribuyeron al progreso del conocimiento, apoyado en hermosas láminas a color. La escritura es también original: se produce un coloquio fraterno entre el autor y el lector, que lleva a este último a una mayor motivación por conocer un tema. Es un arte difícil de alcanzar el mezclar en un solo análisis principios, historia y práctica clínica, ésta es una de las características más sobresalientes de este libro. Si el lector quiere aprender o refrescar conocimientos previos se encontrará más motivado y despertará en él su capacidad de asombro para comprender una enfermedad desde su descripción hasta su tratamiento más moderno. 
Y aquí llegamos a otro aspecto original y distintivo de este libro, como es cuestionar en forma crítica y por momentos apasionada algunos de los conceptos más vigentes sobre el tratamiento de la arterioesclerosis. En lugar de promover fármacos el doctor Lama promueve cambios en los estilos de vida, que son al final de cuentas lo que ha permitido reducir la morbilidad y mortalidad de las enfermedades cardiovasculares en los países desarrollados.

Estamos frente a una "Cardiología de Autor", de comienzo a fin, para disfrutar, compartir o disentir. Pero es un libro original, distinto, necesario en la biblioteca de un médico para afirmar conceptos, estudiar los criterios de diagnóstico y manejo y para motivarnos en la necesidad de refrescar permanentemente las virtudes que deben acompañarnos en el ejercicio de nuestra profesión.

Dr. Ramón Corbalán H. Profesor de Medicina, Facultad de Medicina y Centro de Investigación Clínica, Pontificia Universidad Católica de Chile. 